\title{
Establishment of a negative-positive threshold optical density value for the enzyme-linked immunosorbent assay (ELISA) to detect soluble antigen of Renibacterium salmoninarum in Alaskan Pacific salmon
}

\author{
T. R. Meyers ${ }^{1}$, S. Short ${ }^{1}$, C. Farrington ${ }^{2}$, K. Lipson ${ }^{1}$, H. J. Geiger ${ }^{3}$, R. Gates ${ }^{4}$ \\ 'Alaska Department of Fish and Game, Division of Commercial Fisheries Management and Development, \\ Juneau Fish Pathology Laboratory, PO Box 25526, Juneau, Alaska 99802, USA \\ ${ }^{2}$ Alaska Department of Fish and Game, Division of Commercial Fisheries Management and Development, \\ Region I Office, PO Box 240020, Douglas, Alaska 99824, USA \\ ${ }^{3}$ Alaska Department of Fish and Game, Division of Commercial Fisheries Management and Development, \\ PO Box 25526, Juneau, Alaska 99802, USA \\ ${ }^{4}$ Alaska Department of Fish and Game, Division of Commercial Fisheries Management and Development, \\ 333 Raspberry Road, Anchorage, Alaska 99518, USA
}

\begin{abstract}
Kidney tissues from 5231 chinook salmon Oncorhynchus tshawytscha and 3793 coho salmon $O$. kisutch adults used for spawning were examined for soluble antigen of Renibacterium saimoninarum (Rs) by the enzyme-linked immunosorbent assay (ELISA). The purpose of this study was to develop an extensive data base for establishing a negative-positive threshold optical density value for Rs-negative and -positive fish using commercially available ELISA reagents. Statistical evaluation of the estimated distribution of Rs-negative optical density values from coho and chinook salmon indicated the preliminary estimated negative-positive threshold value of 0.1 was not conservative enough, i.e. there was an unacceptably high probability that a large number of low-level Rs-positive fish were not identified. Consequently, a more conservative threshold value of 0.095 was chosen that erred in Identifying an acceptably low number of negative fish as positive. At this threshold optical density value the ELISA could detect about $20 \mathrm{ng}$ of Rs antigen $\mathrm{ml}^{-1}$ of kidney homogenate.
\end{abstract}

\section{INTRODUCTION}

The enzyme-linked immunosorbent assay (ELISA), used for the detection of Renibacterium salmoninarum (Rs) soluble antigens in salmonid fishes, has been established as a consistent and sensitive method (Pascho \& Mulcahy 1987, Pascho et al. 1987, 1991, Turaga et al. 1987, Sakai et al. 1989). Although useful in the diagnosis of bacterial kidney disease (BKD) caused by the Rs organism, the sensitivity and automation of the ELISA provides a most efficient test for screening large numbers of broodstock for those carrying the Rs agent. Eggs and fry from those Rs-positive parents may either be destroyed or segregated according to the level of antigen detected (Pascho et al. 1991).
The Fish Pathology Section of the Commercial Fisheries Management and Development (CFMD) Division within the Alaska Department of Fish and Game has performed large-scale broodstock culling for the Rs organism over several years by use of the fluorescent antibody test (FAT). After comparing the FAT with the ELISA (Meyers et al. 1993), the ELISA was selected as the better test. We suspected that optical density values of Rs-negative fish kidneys would not be identical or equal to zero, but would range around a population mean in a more or less normal distribution. If this were true, the common practice for selecting a negative-positive threshold using 2 standard deviations (SD) from the mean optical density value of the negative control in a given test may produce consider- 
able error This would depend upon where the negative control fits into the normal distribution of negative population values. Therefore, the objective of this study was to investigate this hypothesis and develop a statistical rationale for establishing a threshold optical density value to identify Rs-negative and -positive fish using commercially available ELISA reagents. The results presented in this report established a large ELISA data base from which such a threshold optical density value was derived.

\section{MATERIALS AND METHODS}

Test fish and tissue samples. Kidney tissues tested were from mature chinook Oncorhynchus tshawytscha and coho $O$. kisutch salmon used for spawning at various locations in southeast Alaska, USA. Samples from both species were comprised of 14 stocks each, 10 of which were hatchery broodfish and 4 of which were native or wild fish (see Table 2). Clearly, the hatchery stocks comprised the bulk of the kidney samples tested for both salmon species. All fish tested had returned to fresh water to spawn except for 276 Unuk River chinook salmon (see Table 2) that matured in saltwater netpens prior to kidney sample collection.

Samples of anterior and posterior kidney tissues, each weighing at least $0.5 \mathrm{~g}$, were excised from individual mature salmon by use of sterile wooden disposable or iodophor-disinfected $(3 \%)$ utensils. Tissues were placed into $60 \mathrm{ml}(2 \mathrm{oz})$ sterile plastic bags and either frozen at -5 to $-10^{\circ} \mathrm{C}$ for later shipment or sent directly to the CFMD pathology laboratories for processing. Bagged samples were homogenized undiluted for about 20 s using a Stomacher (Tekmar, Cincinnati, OH, USA) and were processed for ELISA as described below

FAT. Although less sensitive than ELISA, direct and indirect FAT procedures were used as an additional method to indicate that kidney tissues used for the negative ELISA control were not infected with the Rs organis.m. Protocols used are described in detail by Meyers et al. (1993) except that more fields (50 to 100) were examined at $1000 \times$ magnification.

ELISA. The procedures used in our double sandwich ELISA for the detection of Rs antigen were derived from those described by Pascho \& Mulcahy (1987) and Pascho et al. (1991) for use with commercially available reagents and buffers (Kirkegaard and Perry Laboratories, Inc., Gaithersburg, MD, USA). The modified protocol that we used for Rs detection included the following steps.

The homogenized tissue samples were diluted 1:4 (w/v) with $0.1 \mathrm{M}$ phosphate buffered saline (PBS, pH 7.4 ) tissue diluent containing $0.5 \%$ Tween 20 (PBS-
T20) and homogenized further A $2.0 \mathrm{ml}$ subsample of tissue slurry from each kidney was pipetted into a numbered screw-capped tube (Sarstedt, Inc., Princeton, NJ, USA) and bolled in a water bath for $15 \mathrm{~min}$ Boiled samples were generally stored at -5 to $-10^{\circ} \mathrm{C}$ and thawed the day before testing. Each sample was centrifuged at $6000 \times g$ at $4{ }^{\circ} \mathrm{C}$ for $20 \mathrm{~min}$ and the supernatant was tested in the ELISA

The remainder of the assay was performed with Kirkegaard and Perry reagents and the volume of each reagent was $200 \mu \mathrm{l}$ unless stated otherwise. Briefly, primary polyclonal affinity-purified goat anti-Rs antibody at $1 \mu \mathrm{g} \mathrm{ml}^{-1}$ in coating buffer (0.1 M PBS) was dispensed into welis of plastic 96-well microtiter plates (Costar, Cambridge, MA, USA) by use of a Titertek Autodrop dispenser (Flow Laboratories, Inc., McLean, $V A$, USA). Plates were covered with mylar sealers (Dynatech Laboratories, Inc., Alexandria, VA, USA) and incubated overnight at $4{ }^{\circ} \mathrm{C}$. Unbound antibody was removed by washing the wells 5 times with $0.002 \mathrm{M}$ imidazole buffered saline containing $0.02 \%$ Tween 20. Each tissue supernatant was tested in duplicate. Development of this ELISA by other investigators suggested that temperature differences across the microtiter plate could bias the mean optical density of replicate wells if the samples were applied consecutively in one area of the well plate (Ron Pascho, U.S. Fish and Wildlife Service, Seattle, WA, USA, unpubl.). Concern about this possibility prompted us to minimize any such potential temperature effect by the application of samples in one of the following pairs of wells within each vertical column of the plate: $A-D$, $B-F, C-G, E-H$. Plates with samples were incubated at 22 to $23{ }^{\circ} \mathrm{C}$ (room temperature, RT) for $3 \mathrm{~h}$, then the wells were washed as described above. Affinity-purified anti-Rs antibody labelled with horseradish peroxidase (HRP) was applied to each well at a 1:2000 (v/v) dilution in milk diluent/blocking solution, and the plates were incubated for $2 \mathrm{~h}$ at RT. Unbound conjugate was removed by washing the plates as described above and peroxidase substrate chromogen was dispensed into each well. Each plate was incubated at $37^{\circ} \mathrm{C}$ for exactly $20 \mathrm{~min}$ and the color development was stopped by adding $100 \mu \mathrm{l}$ of double-strength peroxidase stop solution to each well. Optical density values for duplicate samples were determined immediately afterwards using a microplate reader (Bio-Tek Instruments, Inc., Winooski, VT, USA) set at $405 \mathrm{~nm}$ and connected to a personal computer for data storage and later retrieval

Negative controls (Pascho \& Mulcahy 1987) to evaluate reagent performance were loaded in 4 consecutive wells on the first and seventh plates within an assay. Negative kidney controls for ELISA used throughout this study were prepared from a pool of kidney sam- 
ples from 29 clinically normal adult chinook salmon with average optical density values ranging from 0.067 to 0.083 . Undiluted kidney tissue from each fish was homogenized, then all were pooled and processed as described for the experimental samples except that supernatant was dispensed in aliquots of $2 \mathrm{ml}$ and stored at $-80^{\circ} \mathrm{C}$. A color reaction which produced an optical density value of 0.1 was initially selected as the minimum reaction that a tissue sample must produce before a fish would be considered to be Rs-positive (negative-positive threshold). This optical density value was selected by eye from preliminary chinook and coho salmon ELISA optical density values plotted against frequency which produced a bell-shaped distribution curve. The right-sided tail of the curve appeared to break at the 0.1 optical density value. The optical densities of the individual negative control kidneys and that of the pooled negative control (mean = $0.0815 ; n=397$ ) were well below the 0.1 negative-positive threshold optical density. Additional ELISAs performed on the pooled negative control sample using the same commercial reagents but in another laboratory produced similar negative optical density values when compared to ELISA-negative brook trout Salvelinus fontinalis kidney tissues having mean optical density values of 0.07 to 0.072 (Ron Pascho pers. comm.). All negative control kidney tissues were also negative for Rs or other potentially cross-reacting organisms by both the direct and indirect FAT.

Positive Rs control samples, applied to the antibodycoated wells in the same manner described for the negative controls, consisted of a minimum of 4 replicates each of 4 dilutions made from lyophilized heatkilled Rs cells. Before lyophilization, this preparation contained approximately $0.5 \%$ packed cells $\mathrm{ml}^{-1}$ and a protein concentration of $420 \mu \mathrm{g} \mathrm{ml}^{-1}$ (Kirkegaard and Perry Laboratories, Inc., pers. comm.). Dilutions of $1: 100,1: 1000,1: 2000$, and $1: 5000(\mathrm{v} / \mathrm{v})$ made in PBST20 were dispensed in aliquots of $2 \mathrm{ml}$ and frozen at $-80^{\circ} \mathrm{C}$; an aliquot of each dilution was thawed and boiled for each ELISA.

The lowest concentration of the Rs antigen fraction that our ELISA could detect was determined by measuring the optical densities produced by decreasing concentrations of the whole cell positive control antigen suspended in undiluted kidney homogenate; this kidney had been taken from a chinook salmon that was determined by the ELISA to be Rs-negative. Aliquots of the antigen-supplemented and untreated kidney homogenate were processed and tested in the ELISA as described above for the other kidney tissue samples. A profile of optical density values for these samples was compared to the estimated negative-positive threshold value. We did not extrapolate detection limits from a standard curve because optical density values for Rs antigen concentrations apparently do not follow a linear relationship (Ron Pascho pers. comm.). However, the optical density values are related to the Rs soluble antigen concentrations in the tissues (Pascho \& Mulcahy 1987, Turaga et al. 1987) which generally correspond to the severity of Rs infections in field samples (Pascho et al. 1987, Turaga et al. 1987).

Statistical analysis. Replicate optical density values for ELISA-negative samples generally varied by no more than 0.01. Replicate values for ELISA-positive samples varied similarly at lower positive optical densities but variations increased with increasing optical density values.

The mean of replicate optical density values for each unknown fish tissue sample was determined and interassay comparison of these data was accomplished by use of the correction statistic described by Pascho et al. (1987). Although large reagent pools were made to minimize variations within a series of assays, these eventually had to be replenished with new reagents. The correction statistic, using the positive control optical density values for each assay, allowed for adjustment of any minor fluctuations due to new reagents or day-to-day changes in equipment performance. Negative optical densities produced from 5231 chinook and 3793 coho salmon adults were used for these analyses (see Table 3).

We assumed that the corrected (Pascho et al. 1987) optical density values from infected fish came from some probability distribution. Therefore, we let $f(x \mid+)$ denote the probability density function of this distribution and let $\mu_{+}$and $\sigma_{+}$denote the mean and standard deviation, on the original scale of measurement. Similarly, we let $f\left(\left.x_{\mid}\right|^{-}\right)$denote the probability density function of the corrected optical density measurements of the uninfected fish, and let $\mu_{\text {- }}$ and $\sigma_{\text {- denote the }}$

Table 1 Mean ELISA optical density (OD) values for various concentrations of Renibacterium salmoninarum (Rs) protein antigen added to an Rs-negative chinook salmon kidney tissue homogenate. The protein concentration of the undiluted Rs antigen was $420 \mu \mathrm{g} \mathrm{ml}^{-1}$

\begin{tabular}{|lcc|}
\hline $\begin{array}{c}\text { Antigen } \\
\text { dilution }\end{array}$ & $\begin{array}{c}\text { Rs protein } \\
\text { conc. }\left(\mu \mathrm{g} \mathrm{m} \mathrm{m}^{-1}\right)\end{array}$ & $\begin{array}{c}\text { Mean OD } \\
\text { values }\end{array}$ \\
\hline $1: 100$ & 4.20 & 1.056 \\
$1: 1000$ & 0.42 & 0.441 \\
$1: 2000$ & 0.21 & 0.196 \\
$1: 5000$ & 0.084 & 0.139 \\
$1: 10000$ & 0.042 & 0.110 \\
$1: 20000$ & 0.021 & 0.094 \\
$1: 25000$ & 0.017 & 0.087 \\
$1: 30000$ & 0.014 & 0.083 \\
Negative kidney & 0 & 0.075 \\
\end{tabular}


parameters of this distribution. By letting $\pi$ denote the proportion of infected fish in a hypothetical population, then the probability density function of fish that entered into our data base was represented by a 5 parameter density function:

$$
f(x)=\pi f\left(x_{\mid} \mid+\right)+(1-\pi) f\left(x_{\mid} \mid-\right)
$$

Parameters $\pi, \mu_{+1} \sigma_{+1} \mu$ - and $\sigma_{-}$were estimated by means of maximum likelihood using the expectation maximization algorithm as described by McLachlan \& Basford (1988). Both the normal distribution and the lognormal distribution were assumed for $f\left(x_{\mid}+\right)$and $f(x-)$. Other distributions were considered for $f\left(x_{\mid} \mid+\right)$, but these gave inconsistent results.

\section{RESULTS}

\section{ELISA detection limits}

Positive kidney samples had optical densities equal to or greater than 0.1 ranging to off-scale $(>2.8$ ) on the microplate reader that registered up to 4.0 on the computer. Kidney samples selected from those having high optical densities greater than or equal to 1.0 were also consistently positive for Rs by FAT (Meyers et al. 1993). The 0.1 negativepositive threshold optical density value when compared with optical densities for the different concentrations of antigen-supplemented negative kidney tissue samples suggested the detecton limit of the ELISA was about $40 \mathrm{ng}$ of Rs antigen $\mathrm{ml}^{-1}$ of tissue homogenate (Table 1).

\section{Negative-positive threshold}

The total numbers of Rs-positive chinook and coho salmon detected by ELISA during 1988 and 1989 are summarized in Table 2. These data were produced from 37 ELISAs, each done on a different day. Optical density values from 1.4 (38\%) of these assays required correction using the statistic by Pascho et al. (1987). The mean of the negative control samples $(0.0815)$ remained the same whether the correction statistic was applied or not.

The estimated distribution of the optical densities from Rs-negative samples of chinook and coho salmon did not show significant $(p<0.05)$ differences either between years within a fish species or between the 2 salmonid species using pooled data from both years. Consequently, all optical density values from samples classified as Rs-negative were pooled by the maximum likelihood method, forming a symmetric bell-shaped curve that was well approximated by a lognormal distribution (Fig. 1). The mean and variance estimates were nearly the same when either the normal or og normal distribution was assumed for the Rs-negative samples. We feel that the parameters of $f\left(x_{\mid}-\cdots\right)$ and $f\left(x_{\mid}{ }^{-}\right)$itself were well estimated, with the mean near 0.0776 and the variance near $4.7 \times 10^{-5}$. The gradual curve of the right tail of the distribution indicated prob-

Table 2. Antigen prevalences of Renibacterium salmoninarum determined by ELISA for several chinook Oncorhynchus tshawytscha and coho $O$. kisutch salmon stocks in Alaska during 1988 and 1989. nd: not done. Mean optical density values $\geq 0.095$ were considered positive for the Rs antigen

\begin{tabular}{|c|c|c|}
\hline & \multicolumn{2}{|c|}{$\%$ Prevalence } \\
\hline & 1988 & 1989 \\
\hline \multicolumn{3}{|l|}{ Chinook stocks } \\
\hline Crystal Lake & $5.1(103 / 2003)^{\mathrm{d}}$ & $1.2(7 / 578)$ \\
\hline Farragut River (wild) & nd & $23.5(8 / 34)$ \\
\hline Gastineau Channel & nd & $1.6(1 / 62)$ \\
\hline Harding River (wild) & nd & $11.6(5 / 43)$ \\
\hline Hidden Falls & $3.4(4 / 119)$ & $25.9(42 / 162)$ \\
\hline Indian River & nd & $13.6(3 / 22)$ \\
\hline Ketchikan Creek & $15.4(6 / 39)$ & $17.0(27 / 159)$ \\
\hline King Salmon River (wild) & nd & $90.3(28 / 31)$ \\
\hline Medvejie & $13.7(27 / 197)$ & $0(0 / 190)$ \\
\hline Neets Bay & $4.2(18 / 431)$ & $15.5(45 / 291)$ \\
\hline Ohmer Creek & nd & $4.8(6 / 126)$ \\
\hline Sashin Creek (Unuk) & $45.0(53 / 118)$ & $13.6(75 / 553)$ \\
\hline Sashin Creek (Chickamin) & $56.2(27 / 48)$ & nd \\
\hline Tahini River (wild) & nd & $0(0 / 25)$ \\
\hline Subtotal & $8.1(238 / 2955)$ & $10.9(247 / 2276)$ \\
\hline \multicolumn{3}{|l|}{ Coho stocks } \\
\hline Blanchard Lake & $10.5(13 / 124)$ & nd \\
\hline Burro Creek & nd & $3.6(1 / 28)$ \\
\hline Crystal Lake & $1.6(6 / 368)$ & $0.9(1 / 110)$ \\
\hline Deer Lake & nd & $7.3(15 / 206)$ \\
\hline Flemming Spit & nd & $51.4(36 / 70)$ \\
\hline Gastineau Channel & $12.7(8 / 63)$ & $1.7(1 / 60)$ \\
\hline Goose Creek (wild) & $5.0(1 / 20)$ & nd \\
\hline Indian River & $1.2(1 / 82)$ & $2.1(3 / 140)$ \\
\hline Neets Bay & $2.0(2 / 100)$ & $8.5(74 / 873)$ \\
\hline North Thorne River (wild) & $28.6(2 / 7)$ & nd \\
\hline Reflection Lake (wild) & nd & $25.9(64 / 247)$ \\
\hline Rio Beaver (wild) & $9.1(1 / 11)$ & nd \\
\hline Ward Cove & nd & $18.5(5 / 27)$ \\
\hline Whitman Lake & $6.3(59 / 944)$ & $7.0(22 / 313)$ \\
\hline Subtotal & $5.4(93 / 1719)$ & $10.7(222 / 2074)$ \\
\hline Total (both species) & 8.9180 & 0241 \\
\hline ' (Number positive)/(Total & ber examined) & \\
\hline
\end{tabular}


Fig. 1 Lognormal distribution of observed (thin line) and expected (bold line) frequencies for mean Rs-negative ELISA optical density values of kidney tissues from chinook Oncorhynchus tshawytscha and coho $O$. kisutch salmon examined in Alaska during 1988 and 1989. N-P: negative-positive threshold optical densities of 0.095 and 0.1 , respectively

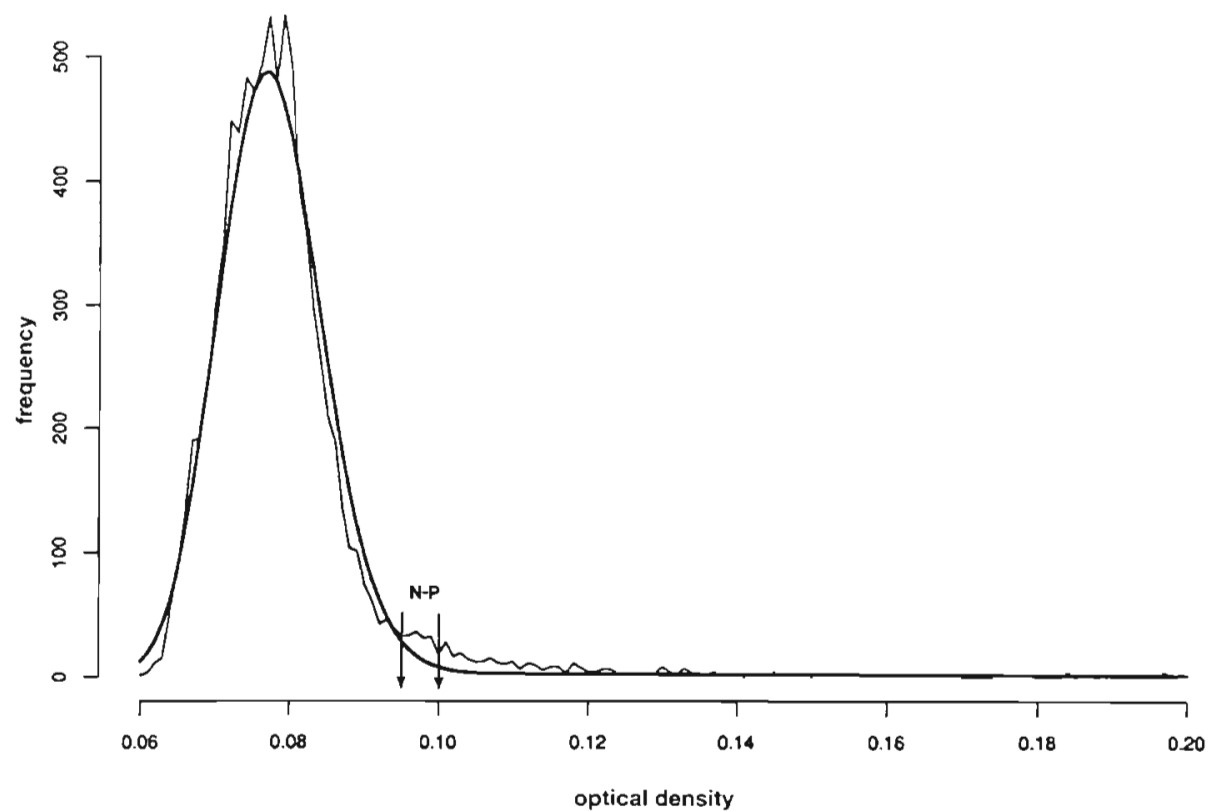

able mixing of negative values with some low-level positive values. However, the estimated distributions of optical densities from Rs-positive samples of chinook and coho salmon showed highly significant variability both between species and between years within species. From this we concluded that the Rs-positive fish did not produce optical density values that were as predictable as those for Rs-negative fish. Optical density values for positive fish did not conform to the maximum likelihood algorithm which, in one example assuming a lognormal distribution for the positive fish and a normal distribution for the negative fish, predicted that $26 \%$ of positive chinook salmon were included in the negative group when the 0.1 negativepositive threshold was used. Because the positive values $(\geq 0.1)$ did not follow a predictable model, the actual number of positive fish that may be in the right tail of the Rs-negative distribution curve (Fig. 1) could not be determined with certainty. Instead, we developed probability values defining the percent of Rsnegative fish likely to be misidentified as positive based upon the estimated parameters of the known Rsnegative sample distribution (Table 3). Our objective was to move as far as possible to the left within the curve's right tail to reduce the number of positive fish categorized as negative without falsely identifying an unacceptably high number of Rs-negative fish as positive. Three different threshold optical density values were tested for both lognormal and normal lognormal transformation of the Rs-negative data. Because the lognormal transformed data provided more conservative estimates, these data were used to evaluate the selected threshold optical density values. The 0.1 threshold optical density allowed 636 fish to be identified as positive and of these the fewest negative fish $(0.18 \%$ or $1 \mathrm{fish}$ ) to be misidentified as positive. But the 0.1 value also allowed an unknown number of low-level positive fish to be identified as negative, which we considered unacceptable. This value $(0.1)$ was $4.4 \mathrm{SD}$ from the mean optical density $(0.0815)$ of the negative control values ( $n=397$ ) and 3.3 SD from the mean optical density of the estimated Rs-negative distribution. The 0.09

Table 3. ELISA statistics for mean negative optical density (OD) pooled values from Alaskan chinook Oncorhynchus tshawytscha and coho $O$. kisutch salmon examined for Renibacterium salmoninarum (Rs) during 1988 and 1989, and the percent of negative fish likely to be identified as positive at 3 different negative-positive threshold OD values. $n=8389$

\begin{tabular}{|lcccc|}
\hline & $\begin{array}{c}\text { Mean } \\
\text { neg. OD }\end{array}$ & Variance & \multicolumn{2}{c|}{$\begin{array}{c}\text { Estimated \% of negative fish identified as } \\
\text { positive at threshold values: } \\
\geq 0.095\end{array}$} \\
\hline Lognormal/lognormal & 0.0776 & $4.7 \times 10^{-5}$ & 2.090 & 1.0 \\
Normal/lognormal & 0.0774 & $4.4 \times 10^{-5}$ & 2.9 & 0.4 \\
\hline
\end{tabular}


optical density (Table 3) would have identified 1060 fish as positive but appeared too restrictive because of the high number of potentially negative fish $14.3 \%$ or 46 fish) that would be among the positive fish. This optical density (0.09) was 2.0 SD from the mean optical density of the negative controls and 1.8 SD from the mean optical density of the estimated Rs-negative distribution. Consequently, the 0.095 optical density (Table 3) would have identified 800 positive fish and seemed to be a better compromise that erred on the side of misidentifying an acceptably low number of potentially negative fish ( $1 \%$ or 8 fish). The 0.095 optical density was $3.2 \mathrm{SD}$ from the mean optical density of the negative controls and $2.5 \mathrm{SD}$ from the mean optical density of the estimated Rs-negative distribution (Table 3). Use of the 0.095 optical density as our new negative-positive threshold would reduce the detection limit of this ELISA to about $20 \mathrm{ng}$ of Rs antigen $\mathrm{ml}^{-1}$ of tissue homogenate (Table 1 ).

\section{DISCUSSION}

The failure of the Rs-positive optical densities to conform to the maximum likelihood algorithm may have been due, in part, to variables for different Rs-infected populations that bias results. For example, certain populations in the data base had very different levels of Rs infection such that many fish in one stock showed low-level positive optical density values whereas in another population the positive fish had high-level optical densities. This bias was compounded further by the variability in the numbers of fish making up each population in the data base and the greater range of variability possible for the positive optical density values than for negative values.

The similarities in the distribution of Rs-negative optical densities for chinook and coho salmon kidney samples observed by statistical analysis suggested that optical density values were not biased by any tissue specificities unique to either fish species. We suspect this relationship may be correctly extrapolated to other Pacific salmon and to other salmonid fishes. We have performed ELISA on all 5 species of Pacific salmon, various trouts and chars, and Arctic grayling Thymallus arcticus and have observed no empirical differences in optical densities. However, our data on these other species have not been extensive enough to allow these observations to be statistically verified. We also observed no apparent differences between optical density values of kidneys or kidney/liver pools (data not shown).

The very close fit of the pooled coho and chinook salmon data to the expected model as well as the similarity of the distribution curves, whether lognormally transformed or not, gave considerable confidence to our data interpretation. Statistical evaluation of the more conservative lognormal distribution of Rs-negative optical densities suggested that the initial 0.1 negative-positive threshold optical density selected in this study was not conservative enough, i.e. there was an unacceptably high probability that a large number of low-level positive fish were not detected. This was emphasized by the data in Table 1 in which known dilutions of Rs antigen elevated the optical density values of a negative kidney to levels still within our estimated distribution of Rs-negative units. However, had we followed the common statistical practice of selecting $2 \mathrm{SD}$ from the mean optical density of the negative control samples for establishing a threshold, this value (0.09) would have misidentified an unacceptable number of negative fish as positive. This also would have assumed that the mean optical density of the negative controls was representative of the mean of the Rsnegative distribution within the population of fish examined. In our data, the negative control mean optical density was very close to the Rs-negative population mean with a SD of 0.6 . For other data sets the untested use of $2 \mathrm{SD}$ beyond the mean of the negative control as a threshold optical density may be a source of considerable error depending upon where in the distribution of the Rs-negative population the controls are selected. If control samples are selected from the left side of the curve (i.e. the lower optical density values), then $2 \mathrm{SD}$ from this negative control mean may still fall well within the Rs-negative distribution and too many potentially negative fish will be considered positive. This shifting of the control values to the left would be the most likely error because the negative controls are not selected randomly but rather for their low optical density values. In certain circumstances, this may not be bad if a decision requires extreme conservatism, such as the transport of fish to a watershed or hatchery that has no known Rs in resident fish stocks. If negative controls are selected from too far to the right of the Rsnegative distribution, some low-level positive fish may be considered negative. This less conservative option may also be acceptable under certain circumstances such as keeping these fish or their gametes at a hatchery where the Rs agent already occurs in the water supply.

Based on the results in this study, we intend to use the threshold value of 0.095 ; this will reduce the detection limit of the assay to about $20 \mathrm{ng}$ of Rs antigen $\mathrm{ml}^{-1}$ of tissue homogenate (Table 1). This sensitivity was slightly better than that of a monoclonal ELISA for Rs (50 to $100 \mathrm{ng}$ antigen $\mathrm{ml}^{-1}$ ) reported by Hsu et al. (1991) but less than the detection limit ( $3 \mathrm{ng}$ antigen $\mathrm{g}^{-1}$ reported by Rockey et al. (1991). An important consideration in establishing such a limit is that there still 
must be some flexibility for changing the threshold optical density value depending upon the degree of conservatism required. In this respect ELISA technology provides a powerful quantitative tool for management of the Rs organism.

Acknowledgements. We sincerely thank Ron Pascho and Dr Diane Elliott for their invaluable help and advice in getting us started in our ELISA work. Also we wish to thank them and Dr Jim Winton for critical review of this manuscript.

\section{LITERATURE CITED}

Hsu, H., Bowser, P. R., Schachte, J. H. (1991). Development and evaluation of a monoclonal-antibody-based enzymelinked immunosorbent assay for the diagnosis of Renibacterium salmoninarum infection. $J$ aquat. Anim. Health 3: 168-175

McLachlan, G. J., Basford, K. E. (1988). Mixture models: inference and applications to clustering. Marcel Dekker, New York

Meyers, T R., Short, S., Farrington, C., Lipson, K., Geiger H. J., Gates, R. (1993). Comparison of the enzyme-linked immunosorbent assay (ELISA) and the fluorescent antibody test (FAT) for measuring the prevalences and levels

Responsible Subject Editor: T. Evelyn, Nanaimo, B.C., Canada of Renibacterium salmoninarum in wild and hatchery stocks of salmonid fishes in Alaska, USA. Dis. aquat. Org. 16: $171-179$

Pascho, R. J., Elliot, D. G., Mallett, R. W., Mulcahy, D. (1987). Comparison of five techniques for the detection of Renibacterium salmoninarum in adult coho salmon. Trans. Am. Fish. Soc. 116: 882-890

Pascho, R. J., Elliott, D. G., Streufert, J. M. (1991). Brood stock segregation of spring chinook salmon Oncorhynchus tshawytscha by use of the enzyme-linked immunosorbent assay (ELISA) and the fluorescent antibody technique (FAT) affects the prevalence and levels of Renibacterium salmoninarum infection in progeny. Dis. aquat. Org. 12 $25-40$

Pascho, R. J., Mulcahy, D. (1987). Enzyme-linked immunosorbent assay for a soluble antigen of Renibacterium salmoninarum, the causative agent of salmonid bacterial kidney disease. Can. J. Fish. Aquat. Sci. 44: 183-191

Rockey, D. D.. Gilkey, L. L., Wiens, G. D., Kaattari, S. L. (1991). Monoclonal antibody-based analysis of the Renibacterium salmoninarum p57 protein in spawning chinook and coho salmon. J. aquat. Anim. Health 3: 23-30

Sakai, M.. Atsuta, S., Kobayashi, M. (1989). Comparison of methods used to detect Renibacterium salmoninarum, the causative agent of bacterial kidney disease. J. aquat. Anim. Health 1. 21-24

Turaga, P., Wiens, G., Kaattari, S. (1987). Bacterial kidney disease: the potential role of soluble protein antigen(s). J. Fish Biol. 31 (Suppl. A): 191-194

Manuscript first received: July 20, 1992

Revised version accepted: April 27, 1993 